\title{
Impact of Green Energy Shares Shocks on Economic Growth and Carbon Emissions in Malaysia
}

\author{
Nora Yusma Bt. Mohamed Yusoff and Nurul Wahilah Bt. Abdul Latif
}

\begin{abstract}
The aim of this paper is to measure the impact of green energy shares shocks in electricity generation on Gross Domestic Product (GDP) and environmental deprivation, caused by the changes in carbon dioxide $\left(\mathrm{CO}_{2}\right)$ emissions. To estimate the shocks of green energy shares, the study applies the dynamic test of Impulse Response Function (IRF) under the VAR methodology. The estimated results show that, in future the increasing portion of green energy's shares in electricity generation would have positive impacts on the environment, as expected. However, the hikes of utilization of green energy sources would incur more cost to electricity producers and shrivel up the growth of economies through the expansionary effect of industry's consumption and private capital spending in the economy. Thus, the study could suggest that for achieving higher economic growth, reducing oil, gas and coal especially in the consumption sectors of the economy and shifting towards indigenous resources would have a beneficial impact on the environment as well as on Malaysia's country balance.
\end{abstract}

Index Terms-Green energy shares, electricity generation, environmental deprivation, carbon emission, economic growth.

\section{INTRODUCTION}

Conventional energy production in Malaysia has been based around oil and natural gas.Malaysia currently has $13 \mathrm{GW}$ of electrical generation capacity. Power generation capacity connected to theNational Grid Malaysia is 19,023 MW, with a maximum demand of $13,340 \mathrm{MW}$ as of July 2007 according to SuruhanjayaTenaga.Total electricity generation in 2007 is 108,539 kilowatt hour with a total consumption of $97,113 \mathrm{GW} \cdot \mathrm{h}$ or $3,570 \mathrm{~kW} \cdot \mathrm{hper}$ capita. The generation fuel mix is $62.6 \%$ gas, $20.9 \%$ coal, $9.5 \%$ hydro and $7 \%$ from other forms of fuel. In 2007 , the country as a whole consumes 514 thousand barrels (23.6 million tonnes) of oil daily against a production of 755 thousand barrels (34.2 million tonnes) per day. However, Malaysia only has 33 years of natural gas reserves, and 19 years of oil reserves, whilst thedemand for energy is increasing. Due to this the Malaysian government is expanding into renewable energy sources. Currently $16 \%$ of Malaysian electricity generations are hydroelectric, the remaining $84 \%$ being thermal.

Application of Green Technology is seen as one of practical solution which are being adopted by many countries around the world to address the issue of energy and environmental simultaneously. In line with that

Manuscript received May 10, 2013; revised July 19, 2013

M. Y. Nora Yusmaand and A. L. Nurul Wahilah are both with Department of Finance \& Economics College of Business Management \& Accounting UniversitiTenagaNasional Sultan Haji Ahmad Shah Campus Pahang, Malaysia Office: +609-4552044 (e-mail: nora@uniten.edu.my, NurulWahilah@uniten.edu.my). objective, a special financing scheme namely, Green Technology Financing Scheme was introduced on 1 January 2010. This will attract the private sector to participate in green technology entrepreneurship to grab new opportunities created by the introduction of the green technology policy.

A various number of empirical studies have been conducted on the short run and long run relationships between energy consumption, carbon emissions and economic growth. However, focus will be made on the most recent available literature in the field of renewable energy consumption, carbon emissions and economic growth. Tiwari (2011) applied panel-data vector autoregression (PVAR) approach to analyze the dynamic relationship between RES and NRES with $\mathrm{CO} 2$ emissions and GDP growth. He found that the impact of RES is to be positive on the growth rate of GDP [1].

Lotfalipour et al. (2010) examined the causal relationships between economic growth, carbon emissions and fossil fuelconsumption, using the Toda-Yamamoto method for Iran during the period 1967-2007. They found that gas consumption lead to economic growth [2], [3]. In the case of India, Tiwari (2011) utilized the technique of SVAR and he provides evidence to support the hypothesis that consumption of RES increases the economic growth of India [4].

On the other hand, Sadorsky (2009) used a panel data model to estimate the impact of RES (which includes geothermal, wind and solar power, waste and wood) on economic growth and $\mathrm{CO} 2$ emissions per capita and oil price for the G7 countries. The author found that, in the long run, real GDP per capita and $\mathrm{CO} 2$ emissions per capita were the main drivers of renewable energy consumption per capita [5]. Sadorsky (2009) also studied the relationship between RES and economic growth in a panel framework of 18 emerging economies for the period 1994-2003 and found that increases in real GDP had a positive and statistically significant effect on renewable energy consumption per capita [6].

Menegaki (2011) studied the causal relationship between economic growth and renewable energy in 27 European countries in a multivariate panel framework over the period 1997-2007 using a random effect model. The author found no evidence of causality between renewable energy consumption and GDP [7]. Lotfalipour, Falahi and Ashena (2010) found that carbon emissions, petroleum products and total fossil fuels consumption do not lead to economic growth [2].

\section{Data Sources and Research Methodology}

\section{A. Data and Variables}

The studywill use annual data of green energy 
sources(GES_TEG), real GDP (RGDP) and carbon emissions $\left(\mathrm{CO}_{2}\right)$ in Malaysia. Yearly data on growth domestic product for 1970-2010 periods will be collected from the Department of Statistics of Malaysia. The green energy sources (GES_TEG) in electricity generation and carbon emissions weretaken from World Bank database. Furthermore, the real GDP was measured in USD constant price (2000 as a base year). All variables are logarithmically transformed and we use logarithmic differences as a proxy of growing rates. This procedure guarantees that all variables are stationary [8]. The current paper utilized the co-integration test and impulse response function (IRF), under vector auto-regression (VAR) framework. The models in this study have been estimated by using the bounds testing (or autoregressive distributed lag, ARDL) co-integration procedure. The data analysis will be conducted by using Microfit and Eviewssoftware.

\section{B. Model Specification}

In this study we focus only in two models which are Carbon Emissions(LCO2) and Real GDP Growth Mode1 (LRGP) in order to assess the impact of green energy shares shocks in electricity generation on real Gross Domestic Product (RGDP) and carbon dioxide $\left(\mathrm{CO}_{2}\right)$ emissions for short run and long run effects. The error correction model representation of the ARDL model can be written as follows:

$$
\begin{aligned}
& \Delta \ln C O 2_{t}=\beta_{0}+\sum_{j=1}^{k} \beta_{11} \Delta \ln C O 2_{t-j}+\sum_{j=0}^{k} \beta_{12} \Delta \ln R G D P_{t-j}+ \\
& \sum_{j=0}^{k} \beta_{13} \Delta \ln G E S_{-} T E G_{t-j}+n_{11} \ln C O 2_{t-1}+n_{12} \ln R G D P_{t-1}+ \\
& n_{13} \ln G E S_{-} T E G_{t-1}+\xi_{t} . .(1) \\
& \Delta \ln R G D P_{t}=\beta_{0}+\sum_{j=1}^{k} \beta_{11} \Delta \ln R G D P_{t-j}+\sum_{j=0}^{k} \beta_{12} \Delta \ln C O 2_{t-j}+ \\
& \sum_{j=0}^{k} \beta_{13} \Delta \ln G E S_{-} T E G_{t-j}+n_{11} \ln R G D P_{t-1}+n_{12} \ln C O 2_{t-1}+ \\
& n_{13} \ln G E S_{-} T E G_{t-1}+\xi_{t} . .(2)
\end{aligned}
$$

The terms with the summation signs in the above equations represents the error correction dynamics while the second part (terms with pijs) corresponds to the long run relationship; $\Delta$ denotes a first difference operator; In represents a natural logarithmic; $\beta_{0}$ is an intercept and $\xi_{t}$ is a white noise.

The dynamic interactions between the green energy shares shocks, real GDP and carbon emissions were analyzed by the IRF which are based on the VAR system. We apply the IRFs (IRF) procedures to simulate one unit standard error shock on current and future values of the variable [10]. GIRFs are more robust as compared to Cholesky decomposition and Orthogonalized IRFs which is sensitive to the ordering of the variables. Specifically, this test is used to determine the extent to which real GDP and carbon emissions responses to agreen energy shares shocks and to what extent these shocks are persistent variables.

According to Sims, if there is true simultaneity among a set of variables, they should all be treated on equal footing; there should not be any priori distinction between endogenous and exogenous variables. It is in this spirit that Sims developed his VAR model. If we performed a causality analysis test and found that we could not reject the hypothesis that there was bilateral causality between $Y_{t}$ and $\underline{X}_{t}$ variables $\left(Y_{t}\right.$ affects $X_{t}$ or $X_{t}$ affects $\left.Y_{t}\right)$ then these kinds of situations are ideally suited for the application of VAR (Gujarati, 2003) [11]. Based on this motivation, the study employed the VAR model proposed by Sims (1980), to simulate a positive standard error unit shock on GES_TEG. In order to explain how a VAR is estimated we assume that each equation contains $k$ lags values of $Y$ and $X[12]$. In this case, one can estimate each of the following equations by OLS:

$$
\begin{aligned}
& Y_{t}=a+\sum_{j=1}^{k} \beta Y_{t-j}+\sum_{j=1}^{k} y Y_{t-j}+U_{1 t} \\
& X_{t}=a+\sum_{j=1}^{k} \delta Y_{t-j}+\sum_{j=1}^{k} y Y_{t-j}+U_{2 t}
\end{aligned}
$$

where the $U_{t}=\left(U_{1}, U_{2 t}\right)$ is the stochastic error terms for $t=1$, $2 \ldots . T$, called impulse or innovations or shocks in the language of VAR. In addition, $U_{1 t}$ and $U_{2 t}$ are assumed independent and with zero mean, i.e. $\mathrm{E}\left(U_{l t}\right)=0, k$ is the lag length criteria, aanda' are drift terms, $\beta, \gamma$ and $\delta$ are the coefficient estimates for independent variables.

Note that the VAR model as illustrated in equation (3) and (4) later will be extended to comprise 3 major endogenous economic variables which are green energy shares use (GES_TEG), real GDP (RGDP) and carbon emissions $\left(\mathrm{CO}_{2}\right)$. In order to measure the shock impact on the VAR system, first we need to identify the order of the integration of the series using a unit root test. Finally, we construct VAR model estimation and plot generalized impulse response function (GIRF) of real GDP growth and $\mathrm{CO} 2$ emissions from the VAR framework to simulate a positive shock to RE.

\section{EMPIRICAL RESULTS AND FINDINGS}

We have estimated the impact of symmetric green energy shares (GES_TEG)shocks that is a standard deviation on real GDP (RGDP) and carbon emissions $\left(\mathrm{CO}_{2}\right)$. These estimations are presented step by step as follows:

\section{A. Unit-RootTests}

This section analyzes the time series properties of the data during the period 1970-2010. We have conducted the Augmented Dickey-Fuller (ADF) unit root tests. This unitsroot test is performed at both levels and the first differences of ADF for all variables, as can be seen in Table I.

Table I shows that all variables have a unit root in their level, since the $p$-value for all series are not significant at all levels. Based on these estimated results, we fail to reject the null hypothesis of unit roots even at the $10 \%$ significance. However when we performed the unit root test at first difference, I (1), the results indicate that all variables are I (1) since the $P$-value is significant at $1 \%$. This means that after we have taken the first difference of all variables, there 
is no evidence of the existence of unit roots. Interestingly, however, first differences of all the variables show stationary under this test.

TABLEI: RESULTS OF ADF TESTS

\begin{tabular}{|l|c|c|}
\multicolumn{3}{|c|}{ AABLEI: RESULTS OF ADF TESTS } \\
\hline \multicolumn{1}{|c|}{ Variables } & Level & 1st Diff \\
\hline LCO2 & -0.470645 & $-7.536717 * * *$ \\
\hline LGES_TEG & -1.349786 & $-5.150590 * * *$ \\
\hline LRGDP & -1.724655 & $-5.546737 * * *$ \\
\hline
\end{tabular}

Note: $* * *, * * *$ denotes sig. level of $10 \%, 5 \%, 1 \%$, respectively

\section{B. ARDL Bounds Test for Long Run Analysis}

The results of the ARDL bounds test in regard to Malaysia are reported in Table II. In the LCO2 and LRGDP model, with LCO2 and LRGDP as dependent variables, we note that the computed F-statistics for Malaysia is above the upper bound critical values provided by Narayan (2005) [13]. Hence, we have strong evidence to reject the null hypothesis of no co-integration at $5 \%$ and $10 \%$ significance level, respectively. It shows that there was a long run relationship between LCO2, LRGDP and LGES_TEG for LCO 2 and LRGDP Model.

\begin{tabular}{ccc}
\multicolumn{3}{c}{ TABLE II: BounDS TEST RESULTS } \\
\hline F-statistics & LCO2 Model & LRGDP Model \\
& $5.3936^{* *}$ & $3.9950^{* * *}$ \\
$1 \% \mathrm{I}(0)$ & 4.770 & 4.614 \\
$\mathrm{I}(1)$ & 5.855 & 5.966 \\
$5 \% \mathrm{I}(0)$ & 3.435 & 3.272 \\
$\mathrm{I}(1)$ & 4.260 & 4.306 \\
$10 \% \mathrm{I}(0)$ & 2.835 & 2.676 \\
$\mathrm{I}(1)$ & 3.585 & 3.586 \\
\hline Notes: *** and *** indicate 10\%, 5\% and 1\% level of significance,
\end{tabular}

Table III presents the long run estimation results. We estimated 2 separate models, for the period of 1970 to 2010. We used the $\bar{R}^{2}$ criterion to find the coefficient of the level variables. The results for Malaysia indicated that there is existence of long run co-integrating relationships among the variablesin LCO2 Model as well as LRGDP Model.

TABLE III: LONG RUN ESTIMATION RESULTS

\begin{tabular}{|c|c|c|}
\hline \multicolumn{3}{|l|}{ Model } \\
\hline \multicolumn{3}{|c|}{ Carbon Emissions Model (1) } \\
\hline \multicolumn{3}{|c|}{ 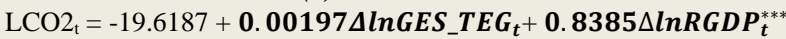 } \\
\hline$(0.61518)$ & $(0.04114)$ & $(0.0436)$ \\
\hline$(-31.891)$ & $(0.4792)$ & $(19.221)$ \\
\hline \multicolumn{3}{|l|}{ Real GDP Model (2) } \\
\hline \multicolumn{3}{|c|}{$\mathrm{LRGDP}_{\mathrm{t}}=22.203^{* * *}+1.0465 \Delta \ln C O 2_{t}^{* * *}+$} \\
\hline$(1.646)$ & $(0.1047)$ & $(0.07607)$ \\
\hline$(13.489)$ & $(9.9916)$ & $(0.92167)$ \\
\hline
\end{tabular}

\section{Error Correction Models for Short Run Analysis}

Short run estimation results in the error correction representations of LCO2 model and LRGDP models are provided in Table IV. The error correction terms $\left(E C_{t-1}\right)$ of the LCO2 model and LRGDP model are statistically significant at the $5 \%$ and $1 \%$ level with appropriate sign (negative), verifying the established co-integrating relationships among the variables. The coefficients of $E C_{t-1}$ measures the speed of adjustment back to the long run equilibrium after a short run shock.

The absolute value of the coefficients of $E C_{t-1}$ in $\mathrm{LCO} 2$ model is fast, indicating the fairly fast speed of adjustment to the long run equilibrium following shortrun shocks.For example, the coefficient of $E C_{t-1}$ is 0.807 in the case of LCO2 Model. This implies that, nearly $80.7 \%$ of the disequilibria in this model of the previous year's shock adjust back to the long run equilibrium in the current year.

TABLE IV: THE ERROR CORRECTION REPRESENTATION ON THE SELECTED ARDL MODEL

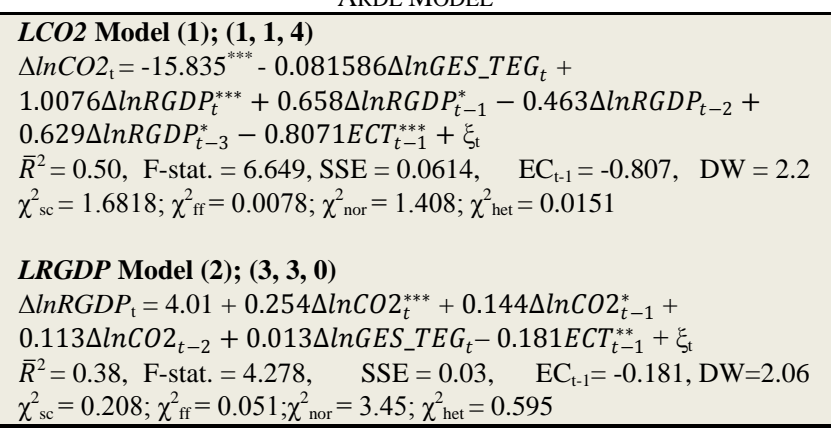

\section{Impulse Response Functions (GIRFs)}

After passed the entire diagnostic and misspecification test on the VAR system, we have performed the Impulse Response Functions (IRFs) in order to simulate a standard error unit shock on GES_TEG. Fig. 1 (a) to 1 (c) shows the IRFs for one standard deviation (SD) symmetric green energy shares shocks (GES) to current and future values of endogenous variables. We conducted estimations of the IRFs over the 10-th period ahead for each endogenous variable based on the VAR system, where decomposition values converging to stable states.

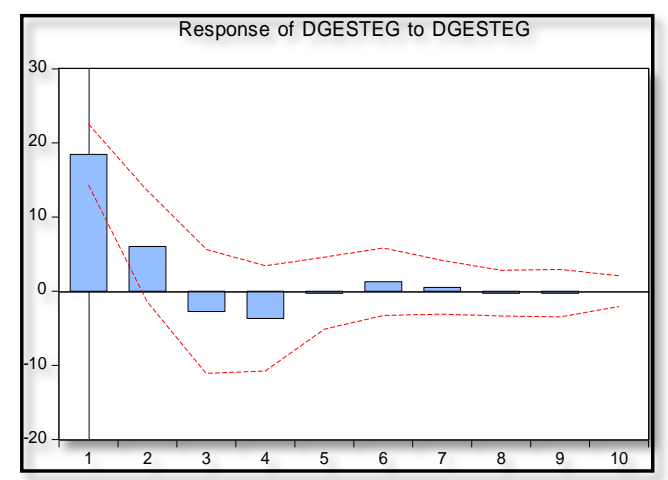

Fig. 1 (a). Response of green energy shocks (GES_TEG) to own shocks.

The impulse response function presented in Figure 1(a) traces the symmetric impact of one unit standard error shock of GES on its own shock. Fig. 1(b) traces the impact of a standard error unit shock of GES on Real GDP. The dynamic profiles of the impulse response suggest that the positive GES shock has an immediate effect on real GDP the next 2-nd period. As far as GES is concerned, we confirm that an increase in GES shock in electricity generation leads to an increased in the real GDP in the short run, as predicted by theory.In other words, the hikes of utilization of green energy sources would incur more cost to electricity producers via technology and input sources investment in electricity generation and shrivel up the 
growth of economies through the expansionary effect of industry's consumption and private capital spending in the economy. The result suggests that real GDP responds symmetrically to GES shock as expected. However, the impact on real GDP growth becomes negative in 3-rd periods before stable or asymptotes to 0 after the 4-th period. This suggests that the symmetric impact of GES shock on the growth rate of GDP is relatively short-lived.

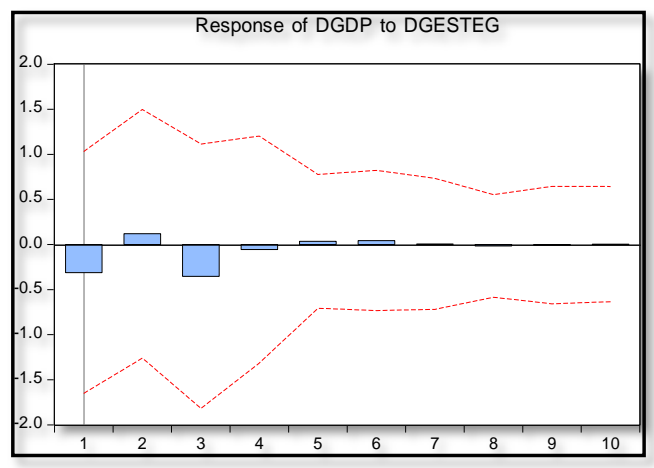

Fig. 1 (b). Response of real GDP to GES_TEG.

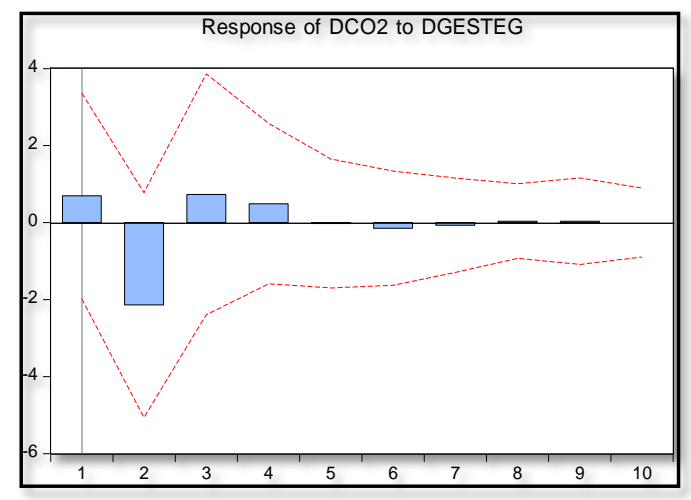

Fig. 1 (c). Response of $\mathrm{CO}_{2}$ to GES_TEG.

It is seen that a positive GES shockin the 1-st period has broughtthe instantaneous negative impact on $\mathrm{CO}_{2}$ emission in the next 2-nd period as presented in Fig. 1(c). There is a substantial increase in the $\mathrm{CO}_{2}$ emissions over the 2-nd period due to the reduction of green energy shares in the 2nd, 3-rd and 4-th before becoming insignificant after the 5the period. It clearly shows that the green energy's share has a negative relationship with $\mathrm{CO}_{2}$ emissions, as expected.

\section{POLICY IMPLICATIONS AND CONCLUSION}

Given the positive effects between green energy shares in electricity generation on $\mathrm{CO}_{2}$ emission and economic growth, government and energy planner should confer prompt response and choose the right mechanism of energy conservation i.e. implementing new energy tax, rules and regulation that can curb fossil fuel use that unfriendly environmental. The study would suggest that for achieving higher economic growth, reducing oil, gas and coal especially in the consumption sectors of the economy and shifting towards indigenous resources mainly, hydropower and biomass would have a beneficial impact on the current account balance. This in turncould decrease the deficit in Malaysia's balance of payment position of the economy in the future.

Therefore, there should be an effort to exploit the renewable sources of energy for consumption and production purposes, which would economize the use of these natural resources in the economy, especially in the industrial sector. This sector consumed 35.7 percent of total commercial energy in Malaysia.The extensive uses of combustion fuel in the industries have contributed massively to the emission of $\mathrm{CO} 2$, a greenhouse gas, into the atmosphere. These gases can exacerbate global warming and lead to environmental destruction and health hazards.

Furthermore, expenditure on green energy and energy efficiency technology should be expanded and treated as an investment in this context. This in turn could help government to reduce domestic consumption of fossil fuel, later could increase the amount available for export. Finally, it is worth pointing out that the results of this paper do no more than suggest that the adoption of expansionary fiscal policy i.e. expenditure on green investment in current and future can facilitate rapid economic growth without conveying a harmfuleffect to the environment. In the sense that, as long as there is a stability and persistence of environmental and economic policies within the framework, a higher expenditure on green investment in Malaysia will contribute positively in supporting the $\mathrm{CO}_{2}$ emission reduction commitments in the Kyoto Protocol 2, as well as achieving an impressive rate of economic growth with environmentally safe.

\section{REFERENCES}

[1] A. K. Tiwari, "Comparative performance of renewable and nonrenewable energy source on economic growth and $\mathrm{CO} 2$ emissions of Europe and Eurasian countries: A PVAR approach," Economics Bulletin, vol. 31, no. 3, pp. 2356-237, 2011.

[2] M. R. Lotfalipour, M. A. Falahi, and M. Ashena, "Economic growth, CO2 emissions, and fossil fuels consumption in Iran," Energy, vol. 35, pp. 5115-5120, 2010.

[3] H. Y. Toda and P. C. B. Phillips, "Vector autoregressions and causality: A theoretical overview and simulation study," Econometric Reviews, vol. 13, pp. 259-285, 1994.

[4] A. K. Tiwari, "A structural VAR analysis of renewable energy consumption, real GDP and CO2 emissions: Evidence from India," Economics Bulletin, AccessEcon, vol. 31, no. 2, pp. 1793-1806, 2011.

[5] P. Sadorsky, "Renewable energy consumption, CO2 emissions and oil prices in the G7 countries," Energy Economics, vol. 31, no. 3, pp. 456-462, ISSN: 0140-9883, May 2009.

[6] P. Sadorsky, "Renewable Energy Consumption And Income In Emerging Economies," Energy Policy, vol. 37, no. 10, pp. 40214028, ISSN: 0301-4215, Oct. 2009.

[7] A. N. Menegaki,"Growth and renewable energy in Europe: A random effect model with evidence for neutrality hypothesis," Energy Economics, vol. 33, pp. 257-263, 2011.

[8] U. Soytas and R. Sari, "Energy demand and GDP: Causality relationship in G7 countries and emerging markets," Energy Economics, vol. 25, pp. 33-37, 2003.

[9] D. Dickey and W. Fuller, "Distribution of the estimators for autoregressive time series with a unit root," Journal of American Statistical Association, vol. 74, pp. 427-431, 1979.

[10] H. H. Pesaran and Y. Shin, "Generalized impulse response analysis in linear multivariate models," Economic Letters, vol. 58, pp. 17-29, 1998

[11] D. Gujarati, Basic Econometrics, 4th Edition, McGraw-Hill, London, 2003.

[12] C. A. Sims, "Macroeconomics and Reality," Econometrica, vol. 48, pp. 1-48, 1980.

[13] P. K. Narayan, "The saving and investment nexus for China: Evidence from co-integration test," Applied Economics, vol. 37, pp. 1979-1990, 2005. 


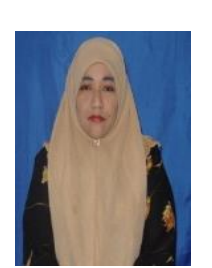

Nora Yusma Binti Mohamed Yusop was born in Kuala Lumpur, Malaysia on 17 August 1971. Currently pursues her Ph.D. studies in Energy Economics (ongoing), University TenagaNasional, Putrajaya, Malaysia. Graduated with M.A (Islamic Finance and Economics) (2003) University Malaya, Kuala Lumpur, Malaysia and B.Econs in Economics and Administration (Hons) (1995). Currently she is a senior lecturer, at Finance and Economics Department, College of Business and Accounting, Universiti Tenaga Nasional, Sultan Haji Ahmad Shah Campus 26700 Muadzam Shah Pahang Darul Makmur, Malaysia.Currently she is a member of International Energy Economics Associations (IEEA) of Unites States, a member of the Malaysia Energy Centree (PTM), a member of the Malaysia Economics Association $n$ (MEA), member of Malaysia Finance and Economics Association. Through joining these associations, she is eligible to subscribe to the many International Journal including International Energy Economics Journals and Economics Journals as well as subscribing Malaysia database for Energy and Economic inputs. She had the opportunities to attend and presenting her research finding at various conferences, workshops, seminars and forum either in Malaysia or abroad.

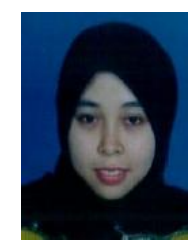

Nurul Wahilah Abdul Latif was born in Perak, Malaysia on $5^{\text {th }}$ January 1975 . She graduated with a bachelor (Econs.), Economics \& Finance (2000) and master (Econs.), Financial Economics (2002). Both degrees arefrom University Kebangsaan Malaysia. Currently she is a senior lecturer, at Finance and Economics Department, College of Business and Accounting, UniversitiTenagaNasional, Sultan Haji Ahmad Shah Campus 26700 Muadzam Shah Pahang DarulMakmur, Malaysia. 